\title{
Outbreak of Tropical Rat Mite (Ornithonyssus bacoti) Dermatitis in a Home for Disabled Persons
}

\author{
J. Baumstark ${ }^{a} \quad$ W. Beck ${ }^{b} \quad$ H. Hofmann ${ }^{a}$ \\ a Department of Dermatology and Allergy Biederstein, Technical University, and ${ }^{\mathrm{b}}$ Institute for Comparative Tropical \\ Medicine and Parasitology, Veterinary Faculty, Ludwig Maximilians University, Munich, Germany
}

Key Words

Tropical rat mite - Ornithonyssus bacoti . Tropical rat mite dermatitis

\begin{abstract}
Five mentally handicapped individuals living in a home for disabled persons in Southern Germany were seen in our outpatient department with pruritic, red papules predominantly located in groups on the upper extremities, neck, upper trunk and face. Over several weeks 40 inhabitants and 5 caretakers were affected by the same rash. Inspection of their home and the sheds nearby disclosed infestation with rat populations and mites. Finally the diagnosis of tropical rat mite dermatitis was made by the identification of the arthropod Ornithonyssus bacoti or so-called tropical rat mite. The patients were treated with topical corticosteroids and antihistamines. After elimination of the rats and disinfection of the rooms by a professional exterminator no new cases of rat mite dermatitis occurred. The tropical rat mite is an external parasite occurring on rats, mice, gerbils, hamsters and various other small mammals. When the principal animal host is not available, human beings can become the victim of mite infestation.
\end{abstract}

Copyright $\odot 2007$ S. Karger AG, Basel

\section{Introduction}

Different mite species, generally found on animals and/or in their environment, may infest humans temporarily; such arthropods should be considered as a possible cause of pruritic and erythematous skin reactions of unclear origin. The tropical rat mite, Ornithonyssus bacoti, is an external parasite occurring on rats (Rattus norvegicus, Rattus rattus), mice (Mus musculus), gerbils (Meriones unguiculatus) and various other small mammals. Although rats are known to be the preferred hosts, infestation of 10 other species of small mammals has been reported. However, in case the principal animal host is not available, human beings may become the victim of mite infestation. The relatively low host specificity might be the reason why laboratory personnel was infested while handling mice [1]. Little information is available about the distribution of tropical rat mite in wild and pet rodents in Europe. The pest arthropods live under tropical and temperate climate conditions. Therefore, its name 'tropical rat mite' is misleading. O. bacoti has been reported from all continents except the Arctic and Antarctic regions as a parasite on small wild, commensal, and laboratory mammals and rodents or on man. The first case report of tropical rat mite in humans from Australia is from 1913 [2]. Furthermore this arthropod was recognized in 1923 as an origin of human dermatitis in the USA. In Germany, O. bacot $i$ was first observed in the Hamburg seaport in 1931, a place indicating the ectoparasite was carried across the world oceans along with infested ship rats or mice, probably in the periods of sailing vessels [3-10]. According to experience in Germany O. bacoti appears on wild and pet rodents more frequently than one might expect [10]. Single case reports from different parts of the world show the presence of this haematophagous pest arthropod also causing dermatitis in humans [2-10].

\section{Case Report}

Five handicapped patients ( 4 male, $1 \mathrm{fe}$ male; age: 22-57 years) living in a home for disabled persons close to Munich were suffering from itching papules developing for approximately 3 weeks. Physical examination of the patients revealed red papules and seropapules, $1-2 \mathrm{~mm}$ in diameter, often surrounded by a pale halo, located in groups or individually predominantly on the upper extremities, neck, upper trunk and face (fig. 1). Some of the papules were excoriated due to scratching. Further physical examination was unremarkable except for the skin lesions. No insects could be found on the skin. According to the accompanying social worker nearly 40

\section{KARGER}

Fax +4161306 1234 E-Mail karger@karger.ch www.karger.com
(2) 2007 S. Karger AG, Basel

$1018-8665 / 07 / 2151-0066 \$ 23.50 / 0$

Accessible online at: www.karger.com/drm
J. Baumstark

Department of Dermatology and Allergy Biederstein

Biedersteiner Strasse 29

DE-80802 Munich (Germany)

Fax+49894140 3578, E-Mail Julia.Baumstark@lrz.tu-muenchen.de 


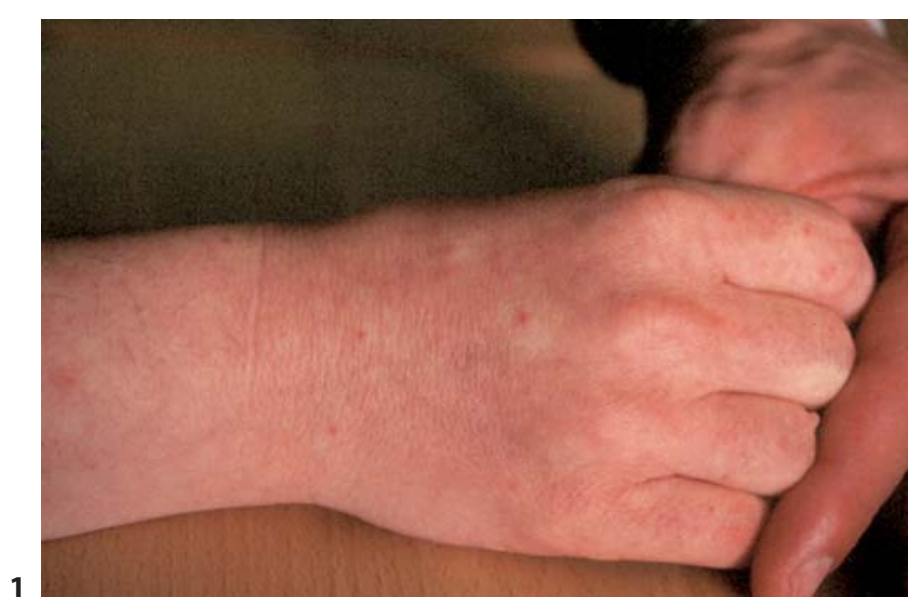

Fig. 1. Pruritic papules on the right hand.

Fig. 2. Tropical rat mite (O. bacoti) from the home of the disabled persons.

of 70 inhabitants and 5 of the employees were affected by itching papules. The diagnosis of insect stings was based on clinical findings. The treatment of the patients was directed towards symptomatic relief. Five of them required oral antihistamines and a topical therapy with crotamiton lotion, and 1 patient in addition received topical corticosteroid and antiseptic ointment.

The home of the patients, the farm and sheds located next to the home, where the garbage is stored in bins for collection, as well as the stable for domestic animals including the storage room for feed were examined. These locations are kept open and are often visited by the disabled. There we discovered distinctive signs of a big population of rats. Inside the sheds lots of mites could be detected in various places. By examination of these mites with light microscopy female and male adults of the species O. bacoti could be identified (fig. 2). Compared to other gamasid mite species belonging to the Macronyssidae, tropical rat mites show a variety of different morphological characteristics.

A professional exterminator was contracted to eliminate the rats in the garden and sheds. All rooms of the home were disinfected, the bedlinen were changed several times and the garbage was collected and eliminated more frequently. After these interventions no more cases of tropical rat mite dermatitis occurred.

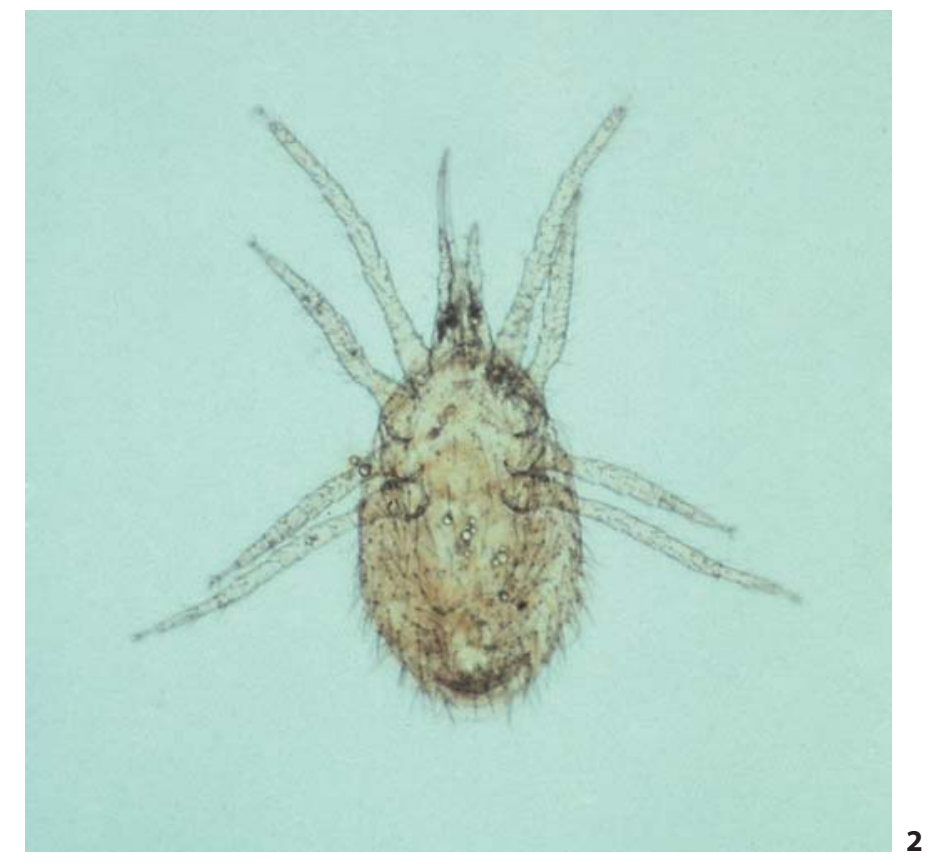

Table 1. Classification of mites (Acari) [18]

$\begin{array}{ll}\text { Parasitic Acari } & \\ \text { Ixodidae } & \text { castor bean tick } \\ \text { Argasidae } & \text { soft-bodied tick } \\ \text { Sarcoptidae } & \text { sarcoptic mange mite } \\ \text { Trombiculidae } & \text { harvest mite } \\ \text { Dermanyssidae } & \text { poultry red mite } \\ \text { Cheyletiellidae } & \text { fur mite } \\ \text { Demodicidae } & \text { follicle mite }\end{array}$

Nonparasitic Acari

Tyroglyphidae

Pyroglyphidae

storage mite

house dust mite

\section{Discussion}

All developmental stages of $O$. bacoti exclusively consume blood. Those parasites induce a nonspecific dermatitis by their mouth parts and saliva components; therefore, it is difficult to diagnose rat mite dermatitis unless the parasites are found. In most cases, the mites are recognized only when they attack humans. In cases of pet rodent infestation or attacked small mammals from household husbandries, veterinary practitioners sometimes see $O$. bacoti on the hosts' integument or environment. The diagnosis of rat mite derma- titis requires detection of the parasite, which is more likely to be found in the environment of its host than on the hosts' skin itself. Therefore, most mites are found in and around the animals' sleeping area and nests, in the floor dust and in clothing [8-11].

O. bacoti belongs to the phylum Arthropoda, class Arachnida, order Acari and superfamily Parasitoidea (table 1). The life cycle of the tropical rat mite includes 5 developmental stages: egg, larva, protonymph, deutonymph and adult. The entire life cycle takes as little as 11-13 days under optimum environmental condi- 
tions; however, protonymphs can survive for 43 days and adults for up 63 days without blood meal $[10,11]$. Female mites reach a size between 0.75 and $1.40 \mathrm{~mm}$, males are a little smaller [13]. Usually those external parasites can be seen with the naked eye when crawling, especially on white backgrounds. The unfed mite is of a grey-white colour and is rather active in movement, but, after having engorged, it is darker, red-brown, and sluggish [11].

The identification of the tropical rat mite requires special knowledge about the morphological characteristics of these arthropods. At first sight, O. bacoti looks similar to Dermanyssus gallinae and Ornithonyssus sylviarum. All 3 mite species are haematophagous external parasites with the same physiology and developmental behaviour, but the preferred hosts of $D$. gallinae and O. sylviarum are wild and domestic birds or bats. These bird-specific mites might also be transmitted onto human skin and cause pruritic lesions. Trop-

\section{References}

1 Fox JG: Outbreak of tropical rat mite dermatitis in laboratory personnel. Arch Dermatol 1982;118:676-678.

2 Cleland JB: Injuries and disease of man in Australia attributable to animals. J Trop Med 1913;16:43-47.

3 Hetherington GW, Holder WR, Smith ED: Rat mite dermatitis. JAMA 1971;215:14991500.

4 Tika-Ram SM, Satija KC, Kaushik RK: Ornithonyssus bacoti infestation in laboratory personnel and veterinary students. Int J Zoonoses 1986;13:138-140.

5 Betke P, Ribbeck R, Schultka H: Diagnostic problems of Ornithonyssus bacoti (Acarida: Gamasida: Macronyssidae) infestation in humans. Angew Parasitol 1987;28:121-126.

6 Tarnick M: Acrodermatosis caused by Ornithonyssus bacoti Hirst (tropical rat mite). Dermatol Monatsschr 1987;173:272-275.

7 Fishman HC: Rat mite dermatitis. Cutis $1988 ; 42: 414-416$ ical rat mites are much more hairy than other mite species. The density of the hair coat of the abdomen is considerably higher in comparison to D. gallinae and O. sylviarum. There are remarkable differences in the shape of the dorsal shield (scutum), sternal and genital shield, position of the anus, number and location of various setae, etc. $O$. bacoti, in contrast to the other 2 mite species, shows a sharp caudal apex of the scutum, an oval genital shield with a cranial positioned anus.

Case reports about tropical rat mite infestation are rarely recorded in the human and veterinary literature, possibly because of the difficulty of detection and accurate identification of this ectoparasite. Futhermore, in contrast to other arthropod stings and bites [14] so far no systemic allergic reactions to tropical rat mite infestation have been reported. Dermatologists are keenly aware of dermatoses associated with mites; particularly when the preferred host is man, as is the case with Sar-

8 Habedank B, Betke P: New findings of tropical rat mite, Ornithonyssus bacoti (Acari: Macronyssidae) - in flats (abstract 44). DVG Tagung: Epidemiology and Eradication of Parasitoses. Travemünde, 2002.

9 Beck W: Mass infestation by tropical rat mite, Ornithonyssus bacoti (Acari: Macronyssidae), in gerbil - experiences to the treatment with selamectin (Stronghold $\left.{ }^{\circledR}\right)$. Kleintierpraxis 2002;47:607-613.

10 Beck W: Detection of tropical rat mite (Ornithonyssus bacoti) on humans in Munich (abstract 46). DVG-Tagung: Epidemiology and Eradication of Parasitoses. Leipzig, 2003.

11 AlexanderJD: Arthropods and Human Skin, ed 1. New York, Springer-Verlag, 1984, pp 303-315.

12 Momcuoglu Y, Rufli T: Dermatologische Entomologie. Humanmedizinisch bedeutsame Milben und Insekten in Mitteleuropa. Erlangen, Perimed-Fachbuch-Verlagsgesellschaft, 1982. coptes scabiei var. hominis, which burrow tunnels into the skin of their host. However, sometimes humans are also vulnerable to less frequently recognized forms of dermatitis caused by ectoparasites parasitic on various animals [15-18]. These dermatoses are often misdiagnosed as prurigo simplex, allergy, unspecific mosquito insect bites or bacterial folliculitis. We believe that the proper identification of epizootic animal mites is important for further treatment. The presence of $O . b a$ cot $i$ is indicative of a rat-infested environment or infested small mammals in flats. Identification allows the physician or veterinarian to advise the patient and/or pet owner on eliminating the origin. Of note, the correlation of systemic symptoms such as eosinophilia and $\operatorname{IgE}$ induction would be of interest to possibly identify typical features of rat mite bites. We hope the new aspects given here will draw attention to this subject.
13 Charlesworth EN, Clegern RW: Tropical rat mite dermatitis. Arch Dermatol 1977;113: 937-938.

14 Bichler AJ: Systemic immediate allergic reactions to arthropod stings and bites. Dermatology 2005;210:119-127.

15 Beck W, Pfister K: Occurrence of a house-infesting tropical rat mite (Ornithonyssus bacoti) on murides and human beings in $\mathrm{Mu}$ nich: 3 case reports. Wien Klin Wochenschr 2004;116(suppl 4):65-68.

16 Beck W, Haghayegh S, Pfister K: Tropical rat mites (Ornithonyssus bacoti) on a pet hamster and on man - a case report. Kleintiermedizin 2004;7:58-62.

17 Creel NB, Crowe MA, Mullen GR: Pet hamsters as a source of rat mite dermatitis. Cutis 2003;71:457-461.

18 Engel PM, Welzel J, Maas M, Schramm U, Wolff HH: Tropical rat mite dermatitis: case report and review. Clin Infect Dis 1998;27: 1465-1469. 